\title{
Era uma vez um menininho torto: desajustamentos sociais e práticas cotidianas
}

Erase una vez un niño inadaptado: desajustamentos sociales y practicas cotidianas

Once upon a time an unfitted little boy: social misadjustment and everyday practices

\section{Carla Lavarda Concentino Caetano}

Universidade Regional Integrada, Santiago, RS, Brasil.

\section{Andrea Scisleski}

Universidade Católica Dom Bosco, Campo Grande, MS, Brasil.

\begin{abstract}
Resumo
Este artigo analisa a produção de uma infância tomada como desajustada, a partir de uma perspectiva crítica sobre as práticas das políticas públicas e dos discursos dos saberes científicos. Tal artigo tem como objetivo problematizar essa situação a partir de um trabalho de pesquisa no campo da Psicologia Social. Como conclusão, entende-se que colocar em questão as próprias práticas e os efeitos da produção de conhecimento em Psicologia torna-se fundamental para desconstruir formas de tratar infâncias de modos desiguais.
\end{abstract}

Palavras-chave: Desajustamento social, Dobra, Infância, Práticas sociais.

\section{Resumen}

En este artículo examina la producción de un niño comprendido como inadecuado, desde una perspectiva crítica sobre la práctica de las políticas públicas y los discursos del conocimiento científico. Este artículo tiene como objetivo hacer una problematización acerca de esta situación a partir de una investigación en psicología social. En conclusión, se entiende que poner en cuestión las prácticas y los efectos de la producción de conocimiento en la psicología es fundamental para descomponer las formas de tratamiento de manera desigual la infancia.

Palabras clave: Inadaptación social, Dobra, Infancia, Prácticas sociales

\begin{abstract}
This article analyzes the production of childhood taken as misadjusted, from a critical perspective about the practices in public policies and from scientific knowledge discourses. It aims to problematize this situation since a research field in Social Psychology. As conclusion,
\end{abstract}


we can notice that is putting into question the own practices made by us and the effects of the production of knowledge in Psychology that it is possible to unbuild ways for handling with unequal childhoods.

Keywords: Social misadjustment, Folder, Childhood, Social practices.

\section{Introdução}

Este artigo nasce de uma pesquisa de monografia em especialização em Clínica e Saúde na Universidade Regional Integrada (URI) em Santiago, Brasil. Cabe dizer que essa investigação se realizou a partir das questões oriundas de uma vivência de Clínica Ampliada, com uma perspectiva teórica e metodológica do campo da Psicologia Social. Com isso, podemos afirmar que com este trabalho não visamos enfatizar somente os aspectos subjetivos e individuais da trajetória de vida de um menino atendido por uma de nós, mas principalmente, nosso foco é colocar em questão o modo como as práticas de atenção em saúde, assistência social, educação, entre outras esferas das políticas públicas, voltadas para a infância e adolescência, operam e produzem efeitos na vida dos sujeitos a que se destinam.

Podemos perceber que a sociedade atualmente exerce diversas formas de exclusão, através de mecanismos extremante sutis. Por meio de discursos que responsabilizam os sujeitos individualmente pelos seus atos - seja através de um diagnóstico que aponta para uma doença que deve ser tratada e medicada, seja através de medidas de correção que colocam os sujeitos sob uma constante vigilância - como se não houvesse uma relação imediata entre os modos de subjetivação e os modos de produção de suas políticas; dessa forma, apresentamos a seguinte questão: Como a sociedade está "aplicando" os seus modos de governar à população jovem? E mais especificamente, como esses modos de governar dirigem a infância tomada como “em perigo" ou "perigosa"?

Através deste trabalho clínico e social, iremos problematizar alguns problemas interligados ao modo pelo qual as políticas públicas fazem cumprir seu "dever" como Estado e, com isso, pretendemos ir além do modelo clínico tradicional, onde se criam patologias individuais, com diagnósticos psicológicos, médicos e medicalizantes e que tratam as "condutas desviantes" a partir de saberes e verdades instaurados.

Para falar desse percurso, consideramos que é necessário dizer um pouco sobre Rogério ${ }^{1}$ É importante 
destacarmos o processo de como a pesquisa foi construída, uma vez que nosso trato se deu diretamente com o menino já em suas primeiras vindas à clínica. Cabe ressaltar ainda, para o entendimento desse processo, como conhecemos o menino. Rogério era "famoso" no município devido às práticas que ele fazia: andava com adolescentes usuários de drogas, participava - muitas vezes acompanhando junto desses adolescentes, outras vezes sozinho - de ações de "arruaças" na cidade (quebrava o vidro da casa dos vizinhos, passava trote telefônico à polícia, etc), de modo que a cidade inteira - principalmente os órgãos públicos, como a escola, o Conselho Tutelar, o CAPS, entre outros já não queria mais ter que lidar diretamente com o "menino-problema". Dessa maneira, a prefeitura da cidade encaminhou o menino à clínica de atendimento onde uma de nós atua criando um convênio para que ele fosse atendido, já que as psicólogas do município se recusavam a atendê-lo. Aliás, essa é uma prática bastante comum no que se refere ao modo de tratar os casos tidos como problemas dos municípios. Assim, iniciou-se o nosso "acordo" com o menino, no qual conversamos com ele sobre a possibilidade de contarmos a sua história em uma forma de pesquisa, da qual decorreu-se como uma monografia e também como este artigo. Nesse sentido, cabe dizer que Rogério pareceu admirado que alguém tivesse interesse em sua história, aceitando verbalmente a participar; no entanto, queremos colocar aqui que entendemos a questão da ética em pesquisa como um processo imanente não se resumindo apenas ao seguimento de trâmites burocráticos - e não apenas à pesquisa estritamente, mas a toda e a qualquer atividade que se dirige ao tratamento a pessoas. Dessa forma, focalizamos o nosso cuidado no atendimento de Rogério a partir dele mesmo, de sua visão e também do modo como temos nos posicionado em pensá-lo e tratá-lo como sujeito. Se tomarmos a ética, como coloca Foucault (2010; 2009; Candiotto, 2010), em termos de um cuidado de si - bem como nas técnicas desse cuidado, como é o caso da Psicologia - se torna fundamental pensar o sujeito em seu contexto, da forma como ele se constitui subjetivamente diante das condições que lhe são possibilitadas para que se torne o sujeito que é e, neste caso, diante também das políticas que lhe governam. No caso de Rogério, ressaltamos, nosso trabalho se constituiu muito mais no de lutar para que outras formas de reconhecimento social sobre sua forma de ser sujeito pudessem emergir, justamente indo contra a reificação de uma posição subjetiva em que ele se encontrava - posição essa destacada pelo modo como era tratado pela sua família e pelas 
instituições que lhe viam como doente e delinquente. Assim, ética, aqui, é exatamente a busca por outra forma de reconhecimento e, acreditamos, a escrita desse texto pode contribuir para que histórias como essas possam ser pensadas eticamente, no sentido de possibilitar e de construir espaços subjetivos para que esses indivíduos que tem o destino tão precipitadamente traçado como delinquentes e marginais possam ser pensados e tratados a partir de uma potencialidade de vida, que os desloquem dessa posição prévia e estanque em uma posição de marginalidade.

Dito isso, ressaltamos que o que segue abaixo é um esboço do "currículo" de Rogério, no sentido goffmiano (Goffman, 1974), já que nessa perspectiva o currículo, analogamente à carreira profissional, expressa como o sujeito vai se desenvolvendo e, através disso, vai obtendo qualificações e reconhecimento social por seus feitos. Apresentamos, dessa forma, os dados curriculares de Rogério:

Nome: Rogério

Idade: 10 anos

Sexo: Masculino

Escolaridade: Nenhuma - Não lê, apenas reproduz letras

Filiação: Não sabe quem é o pai, e foi deixado pela mãe aos cuidados da avó.
Endereço: Mora com a avó, tia e prima e é visto pela família como um fardo a carregar.

Objetivo: Existir de um modo digno, ter direito à escola, serviços de saúde, assistência, cidadania, amor, carinho...

Títulos de Infração:

I. Vidros quebrados na casa e pela cidade;

II. Brigas com as outras crianças na pracinha;

III. Carros arranhados pela cidade;

IV. Agressão à avó;

V. Perturbação a policiais;

VI. Existência.

Grupo de Influência: Outras crianças e jovens marginalizados da sua cidade.

Um acontecimento interessante de expor, referente ao início do atendimento psicológico do menino diz respeito a uma briga, dentre tantas outras, com sua avó. Certo dia, no consultório clínico, situado próximo à casa do menino, a psicóloga que $\mathrm{o}$ atende escutou alguns gritos... e percebeu que o barulho era ele brigando com a avó. Durante algum tempo, os gritos continuaram e, então, uma de nós, que o atendia como psicóloga, se dirigiu até a frente da casa, considerando que as brigas e a agressividade entre a família eram constantes, e que frequentemente aconteciam situações com possível perigo de vida. Chegando lá, o menino estava ameaçando a avó, justificando que havia pedido a ela cinco Reais e a mesma disse que não tinha e que não lhe daria esse 
dinheiro, pois seria para ele ir a uma casa de jogos de videogame. A psicóloga chamou-o mais de uma vez, porém, ele não veio. Então, atendendo ao pedido da psicóloga, uma colega de consultório ligou para o Conselho Tutelar - essa atitude foi tomada no ímpeto de criar uma possibilidade de diálogo com esse órgão, no sentido de uma busca de uma intervenção que pudesse proteger o menino do que estivesse ocorrendo em sua casa. A conselheira que por sua vez disse que viria, mas o Conselho demorou muito, e foi tomada a decisão de conversar-se com ele no consultório. Pouco depois, o menino foi até o consultório e cerca de uma hora depois chegaram dois Conselheiros, enquanto a psicóloga e sua colega já estavam brincando com o menino na sala de ludoterapia; esses Conselheiros ficaram alguns poucos minutos e foram embora.

Repensando a situação, podemos hoje questionar se a ida até à casa do menino naquela ocasião teria sido a atitude mais adequada, se foi correto chamarmos o Conselho Tutelar ou não, etc, mas é necessário dizer que após esse episódio Rogério passou a vincular-se efetivamente com nosso trabalho, demonstrando sentirse protegido e aliviado em constatar que algumas pessoas estavam procurando ajudá-lo e o enxergavam de modo diferente dos rótulos que lhe eram atribuídos pejorativamente por tantas outras pessoas.
Considerando então que esse foi um momento diferencial para construção do vínculo com Rogério, pelo fato de que ele foi acolhido - e não culpabilizado, como freqüentemente o é por outras instituições como a escola, o próprio Conselho Tutelar, entre outros - também se faz necessário contextualizar os aspectos teóricos para o desenvolvimento deste artigo. Lançaremos mão de algumas contribuições das idéias de Donzelot (1986), Goffman (1974; 1988), Foucault (2010, 1999a, 1999b), e Rosane Neves da Silva (2004) entre outros.

\section{Constituição e permanência}

Ao contarmos a história de um "menininho torto", entortado e dobrado por diferentes modos de subjetivação, e através da ideia de que as constituições e construções sociais e subjetivas acontecem somente no encontro entre os campos do fora e do dentro, buscaremos construir o delineamento teórico de nosso trabalho.

As afirmações de Rosane Neves da Silva (2004), são importantes para o entendimento de uma constituição subjetiva a partir do conceito de dobra. Silva (2004), inspirada nas leituras de Deleuze, especialmente na busca de um entendimento do conceito de dobra e da formação, constituição e continuidade, explica que a dobra se manifesta como um caráter coextensivo do dentro e do fora. 
Desse modo, a dobra constitui tanto a subjetividade como o território existencial, quanto a própria subjetivação. A leitura sobre a dobra deleuziana proposta por Silva (2004) se faz pertinente para refletir sobre a experiência subjetiva e as forças de atravessamento que permeiam a construção do sujeito.

Com isso, questionamos como a constituição social atravessa e produz modos de existência àquele que não se enquadra dentro de um padrão de normatização, muitas vezes produzindo modos desiguais de acesso a certos espaços sociais, sejam eles da família, da escola, da cidade e de suas próprias políticas. O que buscamos dizer é que muitas das produções subjetivas são reflexos do modo de como esses campos do fora atravessam o sujeito.

Para Silva (2004) tudo no mundo existe dobrado; ou seja, as múltiplas dobraduras do fora vão produzir distintas maneiras de expressão da subjetividade, que é tomada como "individual". Assim, de acordo com Silva (2004), a noção de dobra deleuziana não é, portanto, isolada do campo social, mas pelo contrário, é indissociada e se dá nesse encontro indiscernível entre o dentro-“sujeito" e o fora-"social".

Essas dobras vão construindo e produzindo modos de subjetivação, através de um equivaler generalizado, defendido inicialmente por um poder disciplinar, onde "qualquer coisa equivale a qualquer coisa" (Silva, 2004 p. 9). Entre esses movimentos de dobragem, há uma força de dupla captura, atravessada pela "divisão" entre o dentro e o fora - produção da dissociação-, pois se trata de modelo que produz dicotomias operadas por uma racionalidade. A dobra desenvolvida através dessa dicotomia, criando um sistema que se sustenta através dessa armadilha semiótica, nos levando a pensar nestas rupturas - "sujeito-mundo"; "indivíduo-sociedade" - e que são determinadas pela relação saber-verdade, própria das ciências modernas, produzindo, assim, modos de subjetivação (Silva, 2004).

A noção de dobra não é deste modo independente do campo social; pensar nesse arranjo, nesses modos de subjetivação é apreender como essas formas de atravessamento, que constituem as dobras e esses processos de dobragem acontecem, tendo a dobra como ponto de inflexão, através do qual o sujeito constitui um tipo de relação consigo, o qual é atravessado pelos campos do fora (Silva, 2004).

Nessa lógica, percebemos que essas "patologias" são muito mais sociais do que individuais, considerando que estes mecanismos de individualização culpabilizam o sujeito, que não se 
enquadra nas organizações institucionais, oferecidas pelo modelo social dominante. Desse modo, parece ser mais "fácil" aplicar um diagnóstico e medicalizar, do que questionar as práticas políticas, médicas, psicológicas, onde os saberes e verdades se constituem e se cristalizam. Foucault (2005) em contraponto a esse pensamento hegemônico de que o conhecimento é algo natural, traz considerações de como estas formas de saber se constituem em meio a uma relação de poder, violação e violência. "O conhecimento só pode ser uma violação das coisas a conhecer e não a percepção, reconhecimento, identificação delas ou com elas" (Foucault, 2005 p.18).

Cabe dizer também que falamos da mudança de nome para a proteção do paciente, neste caso chamamos o menino por Rogério, entre outras questões regulamentadoras que colocam à prova as nossas práticas e atuações, por se referir a uma criança, por levarmos em conta uma proteção à identidade do sujeito, etc. No entanto, os questionamentos de Despret (2009) se fazem importantes nesse momento, uma vez que temos a tendência e a obrigação ética de proteger os nossos pacientes; porém Despret (2009) questiona justamente isto: será que os estamos protegendo, quando escondemos seus nomes? Ou estamos, nós mesmos, nos protegendo com teorias e diagnósticos, para não ter de falar daquilo de mais difícil que encontramos, para mantermos um saber vigente e determinar nossas produções de verdades? "Para dizer simplesmente: a prática do anonimato distribuiu os expertises e constrói, induz ou efetua a assimetria de papéis" (Despret, 2009 p.10). Retomando o acordo de pesquisa que construímos com Rogério, a nosso ver, bem mais importante que os trâmites corriqueiros e burocráticos dos Comitês de Ética é o olhar para o sujeito a partir de sua experiência e criar brechas no espaço social e subjetivo em que ele se constitui que possam lhe oferecer outras possibilidades que saiam dessa recorrência delinquente-marginal-doente. Obviamente não estamos colocando em questão a competência dos Comitês de Ética porque sabemos muito bem que sua criação se deu em prol da proteção de diversas categorias da população que necessitam ser protegidas contra os abusos da ciência, no entanto, também sabemos que a simples execução desses procedimentos não são suficientes para protegê-las efetivamente, até porque o Comitê de Ética é uma instituição acionada para ações de pesquisa, e muitas práticas que se dão fora do campo da ética não se referem à esfera da investigação. A própria história de Rogério elucida bem esta questão pela forma como o próprio município o vem tratando, o modo pelo qual as psicólogas 
da cidade se recusam a atendê-lo justificando que "esse menino não tem jeito", enfim, colocando-o como o único responsável pelo seu "currículo" marginal. Nesse sentido, queremos pôr em evidência que pensar a ética é uma forma de tratar e de pensar o sujeito, extrapolando o contexto estrito da clínica ou da pesquisa, mas justamente contextualizando o sujeito na sua própria existência.

A partir dessa inquietação, retomamos a história de um menino, "como tantos outros", produzida por verdades e distanciamentos. Na busca de um entendimento, apresentamos um pouco da constituição desta história de vida, repleta de solturas, que levam à biografia e ao currículo de Rogério.

Nessa biografia, seguem lapsos da história de vida de Rogério, um menino com dez anos de idade e com uma vida regada de exclusão, negação, infração o que se pode constituir em uma "identidade social deteriorada”. Goffman (1988), afirma que quando uma pessoa traz consigo um estigma em particular, absorve vivências análogas de aprendizagem relativa à sua classificação. $\mathrm{O}$ que lhe determina a contrair mudanças semelhantes em sua concepção de eu, constituindo-se de uma "carreira moral" semelhante que lhe dá uma seqüência similar de ajustamentos pessoais (Goffman, 1988).
Assim, a configuração social é voltada para causar um processo de subjetivação que se incumbe de converter pessoas em meros delinquentes, negando outras possibilidades de vida que escapem às categorias pré-determinadas, com $\mathrm{o}$ intuito de criar diagnósticos e classificações, tais como, "delinquentes", "perfil agravado", "criminosos", "perigosos", e outras disposições que possam ratificar uma posição fechada destes sujeitos (Scisleski, 2010).

Nesse contexto, Scisleski (2010) afirma que as produções diagnósticas, os exames, as entrevistas, as investigações e demais práticas cotidianas, visam normalizar e ajustar os comportamentos produzidos por essa lógica que clama por certeza, na busca de descobrir a causa, a culpa, o delito, a doença e poder, além de descobrir, mostrar, evidenciar, comprovar verdades.

Desse modo, vimos que estamos construindo um sujeito com um destino já traçado, o futuro delinquente que não se adapta a regras, a instituições e a lugares sociais normatizantes. Tal qual podemos ver nas afirmações de Scisleski (2010) a respeito destes prognósticos, ao se referir que a verdade está incorporada com o prenúncio da sina dos sujeitos, aos quais se nomeia, sendo que o conhecimento que é produzido, muitas vezes, existe para adequá-los aos padrões normatizantes e 
para fazer cumprir a "profecia" que proferimos. Diante disso, a autora traz questionamentos sobre os efeitos que a verdade produz na vida desses sujeitos, inspirada nas leituras de Foucault. As práticas da "verdade" originam-se para a formação de elementos que inviabilizam quaisquer afrontas ou questionamentos diante a extraordinária certeza, encontrada diante das formas jurídicas e de saber que ordenam a maneira adequada para lidar com esses sujeitos, formando estratégias de tratamento e de punição e confirmando um "aviso prévio", o qual permite a preconização de uma profecia: "só podia virar um marginal" (Scisleski, 2010, p.35).

A trajetória de vida de Rogério é permeada por uma história de abandono, rejeição e sofrimento e inundada de "verdades". Percebemos que ele "perambula" em diversos médicos, com um novo diagnóstico a cada consulta. Além disso, a cada momento, Rogério não recebe um tratamento continente, pois já foi a consultas psiquiátricas por diversas cidades do estado, já esteve internado em hospital psiquiátrico, em casas de passagens e os serviços aos quais é encaminhado não conseguem estabelecer um espaço de pertencimento e um direcionamento correspondente às necessidades dessa criança.

O que se percebe é que o menino já vem ao mundo como um fardo. Fala-se de uma criança que nasce de uma gravidez indesejada, que não conhece o pai, não vive com a mãe, não frequenta a escola, assim como não frequenta qualquer outra instituição que possa lhe prover um lugar de composição e construção de interioridade "legítima" e possa lhe permitir qualquer espaço que lhe oportunize o que chamamos de cidadania.

Porém, o menino já traz algumas categorizações prévias, como podemos ver na situação a seguir. Havia uma consulta marcada com o psiquiatra e a psicóloga que atendia Rogério foi com ele e com sua avó até o CAPS-AD. A consulta se deu no CAPS-AD porque o único psiquiatra do município tinha disponibilizado horário para atendimento lá. Ao entrarem para consulta, o médico, no início, indaga a avó. Como de praxe, Rogério se levanta e tenta sair da sala, o médico começa a gritar e diz para ele "tu não vai me deixar falando sozinho" e se põe em frente à porta, e continua a dizer "tu vai virar um marginal guri, tu tem que respeitar tua avó, olha só o que tu faz. Se deste tamanho tu já é assim imagina como tu vai ser, vai ser um marginal". Nesse momento o garoto sai da sala, e a psicóloga sai junto, e diz ao médico: "isto não adianta".

$\mathrm{O}$ menino sai andando rápido na frente, a psicóloga vai atrás dele e, após uma quadra aproximadamente, o alcança. Eles se sentam em frente à porta de uma 
casa, na calçada e começam a conversar. A psicóloga diz para o menino não acreditar no que o médico disse, se referindo como "mentira", que poderia confiar nela e no cuidado que eles estavam construindo juntos.

Através dessa situação, podemos pensar nas preconizações das verdades, estudadas por Scisleski (2010), e como elas se instalam em cada sujeito. A ação de enfatizar que as afirmações do médico eram mentira funciona na busca de não deixar que a "profecia dos saberes" se preconize e de que essas forças produzam mais um marginal, tal qual podemos ver na afirmação do médico.

Entre essa ocasião e outros diagnósticos dados que percorrem desde hiperatividade até transtorno de conduta na história de vida de Rogério, o que se vê é que a cada nova consulta surge uma nova "verdade", um novo diagnóstico, o que nos é ainda sempre mais ameaçador que o anterior, pois quando o poder médico não atribui um diagnóstico, surge um problema social, um delinquente em potencial, entre outros nomes que se pode dar aquele que não está sob o controle dos aparatos de saber. Mas quando o diagnóstico não é somente um distúrbio mental e sim aponta para um problema social, como é o caso do "delinquente em potencial", "marginal", entre outros, é pior porque o que traz em questão é a docilidade do sujeito, se o "louco" for dócil a sociedade o "aceita", já o caso do delinqüente é diferente, porque o mesmo afronta e desestrutura a harmonia social.

Quando falamos de uma criança que desde já é tratada de um modo marginal, com "verdades" que o culpabilizam, assim como, nas falas citadas anteriormente pelo médico, vê-se que essas "verdades" interferem e fazem parte do processo de subjetivação, moldando seu futuro.

Retornamos, aqui, a questão da "verdade" como algo construído para cristalização dos saberes e validação de lugares, diagnósticos ou imposições sociais, com o contraponto da "mentira", quando dizemos à criança que as afirmações do médico são mentira, penso sobre a desnaturalização destes lugares diagnósticos validados pelos saberes médicos ao longo da história que servem, de um modo geral, para controle da população, na busca de sujeitos estagnados e pré-determinados. Por isso, quando chamamos as declarações do médico como mentira é no intuito de que este menino se permita pensar sobre si como um sujeito, não tão assujeitado aos valores hegemônicos e de saberes, e sim criar brechas para possibilitar uma pessoa aberta à construção de outras possibilidades e a novas forças de atravessamento. 
Diante disto, entendemos este caso de um modo diferenciado, buscamos fazer um pensar cartográfico sobre nossas vivências ao lado de Rogério, onde a própria prática se constituiu como um modo de realização do trabalho, e este fazer é o nosso método e a nossa ética.

\section{Construções sociais...}

Donzelot (1986) afirma que a família na sociedade ocidental ocupa um lugar singular e questiona sobre qual seriam as junções e as semelhanças entre a extrema disparidade das visões que se pode ter de família e o particular valor social que lhe é conferido. Donzelot (1986), ainda discute sobre o modo que se pode passar das visões singulares ao valor e sobre os meios que se tem para pensar sobre essa construção do valor conferido à família.

Para isso Donzelot (1986) traz uma concepção histórica e política a respeito dos padrões existentes para manter a instituição familiar, protegidas por um ideal burguês e incorporadas em um corpo social como um todo, fundados e mantidos por mecanismos biopolíticos que se utilizam de tecnologias disciplinares para o controle do social e do indivíduo. Para Foucault (1999a, 1999b), a biopolítica é uma nova tecnologia do poder, na qual se exercem formas de governar que visam não só o controle e a regulamentação da população, mas também se utilizam de mecanismos muito sutis sobre os corpos, buscando o controle e a manutenção de uma determinada parcela da população.

Segundo Scisleski (2010), em sua explicação sobre o conceito de biopolítica, as políticas públicas quando pensam a população utilizam o argumento econômico, através desse argumento, usam uma justificativa para execução de uma atividade política, definindo a distribuição de verbas e as instâncias institucionais que deverão receber maior investimento em suas ações. Desse modo, elencam e selecionam as prioridades de investimentos financeiros de suas ações, respectivamente, e com essas decisões direcionam suas atuações a uma determinada população que, por sua vez, lança a forma de vida e prioriza recursos. "Assim, a racionalidade econômica do Estado faz com que essas vidas sejam medidas, calculadas, manejadas, administradas para melhor governá-las.” (Scisleski, 2010, p. 45-46).

Donzelot (1986) afirma que a família se localiza inscrita por meios de pertinência e se torna a menor organização política possível - atribuindo a essa papéis determinados, tais como, a mulher - mãe, deve zelar pelo lar, educar e manter o papel de organizar o lar e ao homem- pai como aquele que deve buscar o sustento de seus entes - e a família por estar aprisionada 
nas relações de dependência, circunscrita nesse processo histórico, que ao mesmo tempo se mantém, como sujeito e objeto do governo. Scisleski (2010) cita Donzelot (2008) para afirmar que nessa lógica o poder é sustentado por mecanismos do liberalismo, tomando a família como uma instância da população a ser disciplinada e a utiliza como instrumento de governo que também opera sobre a área econômica, pois é um argumento, uma força e uma técnica de governo importante na lógica liberal.

Desse modo, foram se criando ao longo do desenvolvimento da sociedade capitalista e burguesa, aparatos disciplinares na busca da regulamentação da população, como um único corpo, os quais se fundam através de valores morais, baseados para o controle e manutenção de formas de governar a população, às quais afirmam os valores familiares, constitucionais, educacionais, como formas de governamentalidade. Sucintamente, podemos dizer que governamentalidade é um conceito desenvolvido por Foucault (2004) para designar as ações de governar populações específicas, tais como crianças, idosos, delinqüientes, órfãos, etc.

Podemos dizer ainda que as políticas públicas atuam também como mecanismos de controle que apontam a família como objeto de cuidado e investimento do governo para, inclusive, sustentar o cuidado e inserção dos filhos na escola e outras instituições que visam à normatização, assim, vão se firmando ações voltadas para a população como um todo. Políticas que são formuladas através de discursos hegemônicos também dos saberes, com o intuito de manter os valores vigentes, na busca da regulamentação da população.

Então questionamos: a família é a base? Isso é o que se tem como referência dos padrões sociais e constitucionais, validados historicamente. Através dos sistemas de valoração é que se atribui à família o dever de tutela e responsabilidade sobre a criança e o adolescente. Porém, se pautam construções montadas por um corpo social dominante e são "empurrados" a todos como valor de norma (Donzelot, 1986).

Ou, ainda, o Estado deve se fazer presente quando a família não tem recursos suficientes para prover o "menor"? Sobre qual o perfil familiar o estado intervém? Daí o questionamento: como essas diretrizes políticas estão atuando em suas práticas? Desse modo, aqui, tratamos de uma criança de direitos? Afinal, para quem se constrói as políticas da infância?

Falamos aqui de uma infância desvalida, que possui dentro de um processo histórico, efeitos de regulamentação diferenciados. Marcilio (2006) afirma que no Brasil, com a 
formação da República, há uma distinção entre a criança rica e a criança pobre, sendo a criança rica, alvo das políticas de educação, saúde e família. Já a criança pobre e abandonada é inserida nas ditas classes perigosas e estigmatizada como "menor", sendo tratada a partir de políticas voltadas ao controle, especialmente através do cuidado de médicos higienistas e juristas. Dessa forma, Marcilio (2006) demonstra a construção da infância e o lugar que a criança ocupa na sociedade, com distinções e tratamentos políticos diferenciados.

O primeiro código de leis firmado no Brasil para crianças é o Código de Menores de 1927, que foi preparado para o controle da infância e da adolescência delinquente e abandonada, sendo que aquele que tivesse menos de 18 anos de idade "abandonado ou delinquente" deveria ser submetido pela autoridade competente a medidas de assistência e proteção, as quais previam que ao menor delito dos pais, o juiz poderia lhe retirar o poder pátrio. Sendo assim, o juiz tornou-se uma figura assustadora ao destino da infância desvalida (Marcilio, 2006).

Verifica-se que no Brasil, até a década de 1960, o Estado não operava em função de proteção da infância desvalida, governava com o lema de "vigiar e punir", regia-se na lógica de repressão aos desviantes. Segundo Marcílio (2006), para que essas funções fossem cumpridas, o Estado brasileiro foi instituindo órgãos e instituições públicas especializadas, qualificadas por uma descontinuidade, com ações políticas ineficientes e incompetentes.

Portanto, na década inaugurada em 1960, o Estado brasileiro tornou-se o grande interventor e o principal responsável pela proteção e assistência da infância pobre e desviante. Em 1964, sob o poder do militares, cria-se a Fundação Nacional do Bem-Estar do Menor (Funabem) que coloca o Estado como interventor nos assuntos da assistência à infância, tendo como função formular e programar a política nacional do bem estar do menor (Marcilio, 2006).

Nesse contexto, através da pressão pelo cumprimento das diretrizes da Declaração Universal dos Direitos da Criança e de organizações não governamentais internacionais, germinava uma nova postura à proteção e bem-estar da criança como direito e dever do Estado. Tendo em vista essa nova perspectiva, em 1979, foi elaborado o segundo código de leis, o Estatuto de Menor, oficializando o papel da Funabem que visava, nesse momento, não só atender às condições dos desvalidos, delinquentes e abandonados mas, também, à adoção de meios propensos a corrigir ou a prevenir as causas do desajustamento. Nesse novo 
código, as entidades de assistência ao menor eram regidas pelo Poder Público, com centros especializados designados para triagem, atendimento, observação e permanência dos menores. Nessa conjuntura social surgem as Febems e congêneres (Marcilio, 2006).

Em 1980, diversos grupos se uniram em defesa dos direitos da criança e do adolescente que, segundo a autora, eram comumente violados pela polícia ou pelas Febems. Com a movimentação dessas forças e discursos de que é dever do Estado tirar as crianças das ruas e dos desvios da marginalidade, levá-las à escola, fazer com que retornem ao seio da família, então foi que entre 1988 e 1990 criou-se o Ministério da Criança e o Estatuto da Criança e do Adolescente, cujos endereçados não eram mais os "menores" e sim a criança e o adolescente, sem distinção. Nesse período, ainda foram sendo criados outros órgãos em substituição as Funabems para sua extinção progressiva. "O governo continuava tratando os assuntos da infância de forma pontual, aleatória, descontínua e muitas vezes inconseqüente" (Marcilio, 2006 p. 227).

Por fim, tais reflexões nos colocam justamente na problematização desse trabalho, pois buscamos compreender ou ainda simplesmente enfocar e problematizar as diferenças entre discursos e práticas para políticas públicas voltadas para a criança e o adolescente. Marcilio (2006) afirma que o ECA foi percebido como um dos Estatutos mais avançados atualmente e, para a autora, deve-se reconhecer que no âmbito das leis o mesmo representou um grande acontecimento, proporcionando condições judiciais para uma reelaborarão das políticas públicas voltadas para a infância e a juventude. E que as políticas de assistência são dirigidas a toda criança que dela necessitar, tratando agora, em tese, de sujeitos de direito (Marcilio, 2006).

No entanto, muitas práticas como a que vemos no caso do atendimento a Rogério, operam no sentido oposto, contrariando os pressupostos legais do Estatuto da Criança e do Adolescente, e ratificando que ainda restam, em nossa sociedade atual, resquícios dessas concepções de "menor".

Até agora, mostramos uma concepção histórica de como essas leis vêm sendo regidas ao longo do tempo, dentro de um processo cronológico. Porém, Bulcão (2002) nos convida a uma aventura em busca do entendimento sobre a produção da infância no Brasil trazendo considerações sobre como esse "conceito" foi sendo construído ao longo do tempo, fazendo-nos refletir sobre a construção da diferenciação entre "menor" e "criança", e que nos coloca em um processo de análise, 
não somente histórico, aparente, mas sim em um processo de apreciação dos acontecimentos, por meio de uma análise mais aprofundada, sobre como as relações, poder/saber se fazem presentes ao longo do tempo, no que se refere à formação da "criança" e do "menor".

Diante desse olhar mais aguçado sobre o modo como as concepções sobre "criança" e "menor" vem se modificando, pode-se perceber uma nova visão de criança e de família, agora a criança é o futuro cidadão e para isso deve ser normatizada de acordo com o modelo social vigente, para torna-se útil $\mathrm{e}$ produtiva (Bulcão, 2002).

De acordo com esse pensamento, Coimbra (2001) afirma que os modelos vigentes na sociedade capitalista necessitam de uma exclusão de diversos setores da população; assim, o capital produz miséria e que, nessa concepção de organização social, é importante que ela exista, uma vez que em sua lógica de funcionamento é necessária a constituição da pobreza.

Dessa forma, a própria formação de alguns espaços sociais urbanos $\mathrm{e}$ as concepções que relacionam as chamadas “classes perigosas" à miséria não se apresentam como algo ligado ao indivíduo, mas, algo que é produzido pelo próprio capital de forma cada vez mais clara nas sociedades, de modo que a pobreza é forjada em uma articulação também com o crime, de modo que se produz como evidente a relação pobreza e criminalidade, como se fossem fatores co-existentes e prédeterminantes para uma forma de existência delinquente e desviante (Coimbra, 2001).

Nesse contexto, surge a preocupação com as crianças que perambulam pelas ruas e com 0 crescimento da criminalidade infantil. Juristas e entidades de bem-estar social se apoderam desses discursos, os difundindo através de escritos e palestras, sendo os juristas "responsáveis" pela introdução do termo "menor" e sua associação com a infância pobre, uma vez que, através de suas leis, popularizaram o uso destes termos, desse modo, reforçando a produção de infâncias desiguais (Bulcão, 2002).

O que se vê, de modo geral, é o desamparo dos lugares que deveriam prover ao sujeito-criança que precisa de cuidados e de espaços de pertencimento em determinadas instituições. Considerando o modelo de infância na sociedade atual, mostraremos um pouco mais como estes espaços se constituem.

\section{Instituições, um espaço de que?}

Mostrar cada espaço como um lugar de circulação de Rogério é uma tentativa de apropriar a dinâmica da cidade 
aos modos de permanência nesses lugares e também uma busca de desconstruir alguns modos de existência já predeterminados.

Atualmente, podemos ver algumas mudanças em Rogério, por exemplo, ele está brincando mais e criando novas amizades. Porém, isso não é dito, disso não se fala, "não se percebe". Na cidade onde ele vive o seu lugar de exclusão vigora na percepção daqueles que valorizam seu lugar como marginal e o apontam como o "menor" e delinquente. Mas, quando há uma nova briga ou outro vidro quebrado, Rogério aparece com toda pompa e circunstância, com os dizeres e saberes que se reafirmam. "Este guri não tem mais jeito mesmo"; ele já é percebido desta maneira, "podemos fazer isto por outros", talvez, mas "ele já está com seu destino traçado, ele é o marginal, o excluído e o inadequado".

Referimo-nos que este guri é uma criança abandonada por todos, inclusive, por nós mesmos profissionais, quando não insistimos em seu tratamento. Porém fazemos um novo questionamento: Por que o abandonamos?

Nós enquanto profissionais, também estamos abandonados à medida que somos imersos em uma cultura com produções morais que se configuram de uma forma onde se retifica uma produção de rupturas sociais, onde os padrões de exclusão predominam. Para manter espaços sociais separados, onde há o "bom" e o "mau", o "certo" e "errado", entre outras produções maniqueístas pautadas por construções voltadas para a “defesa da sociedade". Como podemos ver em Foucault (1999a) ao afirmar que essas formas de regulamentação política e social funcionam muito mais para a proteção de uma parcela da sociedade, que "cria" as regras através de mecanismos normatizadores, que visam o controle dos corpos para a proteção e bem-estar de uma determinada parcela da população à custa da exclusão de outras.

Desse modo, podemos afirmar que as instituições são espaços de normatização e tem, com isso, uma função de ajuste dos sujeitos em suas regras de pertencimento. Porém, quando os sujeitos não se enquadram a esses padrões, tornam-se um problema a ser resolvido e normatizado novamente para que se adaptem às regras de um modelo vigente.

\section{Construindo caminhos: aonde se pode ir?}

Entender que há um sistema de leis que comunga para o "bem" da população sob a nossa ótica é pensar na política como um "bem comum". Mas o que conseguimos ver ao longo de nosso trabalho é que os aparatos políticos 
funcionam em defesa da sociedade que lhes interessa. Assim, consideramos que as regulamentações políticas se desenvolvem a cada dia através de novos estatutos, leis e outras formas de tecnologias sociais sempre na busca de regulamentação da população para que o Estado continue exercendo seu poder regulamentador e as práticas de divisão prossigam a cada novo movimento para que uma nova ordem se propague, normatize e normalize. $\mathrm{O}$ que pretendemos demonstrar, com isso, é que as verdades só existem para justificar os saberes e de que as coisas no mundo só existem por essa constituição semiótica que há neste nosso mundo de signos.

Sobre Rogério, neste momento, o que podemos dizer é que muitas de suas produções em alguns lugares são reflexos do modo como os campos do fora foram atravessados nele e o "dobraram". Assim, à medida que os campos do fora permitem possibilidades de mudança às formas de estar interiormente e exteriormente em "conexão" com a cidade permitem que os "desajustados" circulem pelos os ambientes cotidianos da mesma sociedade.

Também nos perguntamos: $\mathrm{O}$ que fazer com um menino de dez anos de idade que se constitui de um modo "inexistente"? E que traz consigo um modo de relacionarse com os campos do fora inundado de categorização, tais como, "o gurizinho que bate nas outras crianças da pracinha", "a criança que bate na Avó", "aquele que quebra vidro", entre outros processos que fazem dele uma pessoa de uma biografia extensa e desacretidata, com um currículo que o preconiza num futuro marginal.

Ao pensarmos em uma resposta, vimos algumas construções, pois nesse mundo está cheio de tratados e posições que devem ser ocupados para preencher o currículo da existência. Rogério é um menino desamparado e tratado como o "menor", “delinquente", preso a concepções do início do século XIX, tais como as resoluções do código do menor e ratificado por outras categorizações que mudam somente de nome, mas continuam a tratar sujeitos como objeto do saber e inclusive prestigiam e "valorizam" todo um discurso moral ao longo da história. $\mathrm{O}$ que vimos com isso é que se mudam os nomes e os discursos, mas a práticas, muitas vezes, continuam a classificar sujeitos de modo que os engessam a uma identidade ameaçadora da harmonia social.

Ao longo deste percurso, podemos ver que, muitas vezes, estamos em um movimento contrário, como se estivéssemos "remando contra a maré", pois cada vez mais vimos uma sociedade normatizadora e normatizante que, através de aparatos sociais e forças políticas, produz modos de subjetivação específicos e forjados por suas forças de saber. E quando nos colocamos na busca de 
destituir alguns espaços sociais classificatórios e classificantes, nos vemos de "mãos atadas" à medida que encontramos muitos entraves em nossas redes de apoio. Desse modo, continuamos a andar na contramão, na busca de uma nova posição não aprisionada pelos aparatos de saber e sim como profissionais andantes, que estão a questionar as verdades hegemônicas validadas pelos dispositivos de saber.

Através deste artigo, colocamos a nossa posição de acreditar que o psicólogo que atua na clínica - sempre ampliada não pode seguir em uma redoma protegida de um contexto social, pensando em seu "paciente" apenas no que tange ao setting terapêutico, tomando suas questões somente como algo referente a uma "psiquê individual", principalmente quando se tratam de casos como este que apresentamos. Pensamos que a ética exige que o psicólogo aja, se posicione, e não apenas se "esconda" dentro de seu consultório a quatro paredes. Acreditamos que as ações e os posicionamentos adotados precisem evidenciar um articulação entre prática e teoria que sejam coerentes com a defesa da vida, seja ela qual for. Com isso, pretendemos questionar como atuações cotidianas produzem formas de enquadramento dos sujeitos, ainda mais quando tratamos de crianças, pois falamos de sujeitos em construção e construídos diretamente pelos atravessamentos dos campos do fora, os quais se ligam diretamente com suas produções de dentro, produzindo assim subjetividades e modos de ser, constituindo uma interioridade individual. Então, consideramos que nossas práticas em Psicologia devem funcionar na tentativa de desnaturalização desses padrões hegemônicos que tendem a construir sujeitos com subjetividades pautadas como patologias. Propomos, desse modo, pensar a pessoa como alguém em construção, não terminado nem engessado por dispositivos do saber ou verdades diagnósticas. Finalmente, pensamos nossa prática como uma ética, na tentativa de modificar lugares já instaurados e demonstrar como as atuações cotidianas podem transformar espaços impostos, social e historicamente, mesmo que andemos na contramão da grande maioria, que está do lado do "bem" e que caminha "em defesa da sociedade". Dessa maneira, o que colocamos em xeque é como as forças de atravessamento constituem modos de subjetivação, sejam através de suas políticas sociais, práticas de saber ou qualquer outra forma de classificação. Por fim, neste trabalho, o que fazemos é pensar a Psicologia como uma ciência de potência e criação, possibilitando que os sujeitos sejam vistos como pessoas em construção, não 
capturados por diagnósticos, mas como seres em devir.

\section{Notas}

1 Este nome é fictício e é utilizado para preservar a identidade da criança.

\section{Referências}

Candiotto, C. (2010). Ética e política em Michel Foucault. Trans/form/ação, Marília, v. 33, n. 2, pp. 157-176.

Coimbra, C. (2001). Operação-Rio: o mito das classes perigosas. Rio de Janeiro: Intertexto.

Despret V. (2009). Leitura etnopsicológica do segredo: Segunda parte: o efeito sem nome. Conferência apresentada, UFRJ.

Donzelot, J. (1986) A polícia das famílias. 2. ed. Rio de Janeiro: Graal.

Goffman, E. (1988) Estigma: notas sobre a manipulação da identidade deteriorada. Rio de Janeiro: Editora Guanabara.

Goffman, E. (1974). Manicômios, prisões e conventos. São Paulo: Perspectiva.

Foucault, M. (2010). A hermenêutica do sujeito. São Paulo: Martins Fontes.
Foucault, M.. (2005). A verdade e as formas jurídicas. Rio de Janeiro: Nau.

Foucault, M. (1999a). Em defesa da sociedade - Curso no Collége de France (1975-1976). São Paulo: Martins Fontes.

Foucault, M. (1999b). Vigiar e Punir - Nascimento da Prisão. Petrópolis: Editora Vozes.

Lei Federal $\mathrm{N}^{\circ} 8.069$ de 1990. (1990, 13 de Julho) Estatuto da Criança e do Adolescente. Dispõe sobre o Estatuto da Criança e do Adolescente e dá outras providências. Brasília-DF

Marcílio, M. (1998) História social da criança abandonada no Brasil. São Paulo: Hucitec.

Nascimento, M. L. (2002). PIVETES: A produção de infâncias desiguais. Niterói: Intertexto; Rio de Janeiro: Oficina do Autor.

Scisleski, A (2010). Governando vidas matáveis: As relações entre a saúde e a justiça dirigidas a jovens em conflito com a lei. Tese de Doutorado. Pontifícia Universidade Católica do rio grande do sul Programa de pós-graduação em psicologia Silva, R A. N. A dobra Deleuziana: políticas de subjetivação. In: Revista do Departamento de Psicologia UFF. Niteroi, RJ Vol. 16, n. 1 (Jan./jun. 2004), p. 55-75

Carla Lavarda Concentino Caetano: Psicóloga e especialista em Clínica e Saúde pela Universidade Regional 
Integrada e das Missões - URI/Santiago,

RS-Brasil.

Andrea Scisleski: Psicóloga, Mestre em

Psicologia Social e Institucional pela

UFRGS. Doutora em Psicologia pela

PUCRS. Professora do Programa de Pós-

graduação em Psicologia da Universidade

Católica Dom Bosco.

E-mail: ascisleski@yahoo.com.br 